\title{
HVOF and Laser-Cladded Fe-Cr-B Coating in Simulated Biomass Combustion: Microstructure and Fireside Corrosion
}

\author{
Liam Reddy ${ }^{1} \cdot$ Philip Shipway $^{1} \cdot$ Colin Davis $^{2}$ • \\ Tanvir Hussain ${ }^{1}$ (D)
}

Received: 19 January 2017/Published online: 7 April 2017

(C) The Author(s) 2017. This article is an open access publication

\begin{abstract}
Biomass is often considered as a low carbon alternative to fossil fuels in the power industry. However, the heat exchangers in biomass plants can suffer from chloride-based aggressive fireside corrosion. A commercially available amorphous $\mathrm{Fe}-\mathrm{Cr}-\mathrm{B}$ alloy was deposited onto a stainless steel substrate by HVOF thermal spray and laser cladding. The controlled environment corrosion tests were conducted in a $\mathrm{HCl}$-rich environment at $700{ }^{\circ} \mathrm{C}$ for $250 \mathrm{~h}$ with and without $\mathrm{KCl}$ deposits. The samples were examined with XRD, SEM and EDX mapping to understand the corrosion mechanisms. In the absence of any deposits, the amorphous HVOF coating performed very well with a thin oxide growth, whereas the crystalline laser cladding suffered from $\sim 350 \mu \mathrm{m}$ metal loss. The scales were composed of $\mathrm{MnWO}_{4}, \mathrm{Fe}_{2} \mathrm{O}_{3}, \mathrm{Fe}_{3} \mathrm{O}_{4}$ and $\mathrm{Cr}_{2} \mathrm{O}_{3}$. When a $\mathrm{KCl}$ deposit was present, the HVOF-sprayed coating delaminated from the substrate and $\mathrm{MnCl}_{2}$ was found in the scale.
\end{abstract}

Keywords Biomass $\cdot$ Laser cladding $\cdot \mathrm{HVOF} \cdot \mathrm{Fe}-\mathrm{Cr}-\mathrm{B}$

Tanvir Hussain

tanvir.hussain@nottingham.ac.uk

Liam Reddy

liam.reddy@nottingham.ac.uk

Philip Shipway

philip.shipway@nottingham.ac.uk

Colin Davis

colin.davis@uniper.energy

1 Faculty of Engineering, The University of Nottingham, University Park, Nottingham NG7 2RD, UK

2 Materials and Corrosion Team, Technology Centre, Uniper Technologies Limited, Ratcliffe on Soar, Nottingham NG11 0EE, UK 


\section{Introduction}

As a greenhouse gas, $\mathrm{CO}_{2}$ is a major contributor to global warming. National and international legislation is in place with the aim of reducing the amount of $\mathrm{CO}_{2}$ emitted [1]. The power industry, as a major producer of $\mathrm{CO}_{2}$, is under pressure to decrease emissions whilst also increasing the efficiency of generation. One approach taken is to replace fossil fuels with biomass as a feedstock in conventional steamgenerating units. Biomass is often considered a carbon neutral fuel source as the $\mathrm{CO}_{2}$ it releases is offset by the $\mathrm{CO}_{2}$ captured during its lifetime [2].

Fireside corrosion is the major cause of boiler down time in all industrial boilers, but particularly in those firing biomass [3]. A loss of material from the heat exchange surfaces can lead to component failure, either as a direct result of this metal loss, or through mechanical failure instigated by the formation of cracks [4]. The combustion of biomass can lead to the formation of corrosive combustion gasses such as chlorides as well as aggressive deposits on the heat exchange surfaces. This is a major cause of fireside corrosion in biomass-fired power plants [5]. An approach currently taken to reduce fireside corrosion resulting from the combustion of biomass is to operate boilers at a lower temperature where the degree of fireside corrosion is acceptable [6]. Another approach is to use corrosion resistant nickel-based alloys or other protective coatings and claddings to minimize wastage without the drop in efficiency associated with a lower operating temperature. There are a range of surface engineering techniques that can be used to produce these coatings, each with their own benefits.

High-Velocity Oxy-Fuel (HVOF) spray is a thermal spray process in which a combustible fuel is fed into the combustion chamber of the spray gun along with oxygen. In the chamber, the fuel is burnt and the hot expanding gas is forced out of the nozzle at supersonic velocities. The powder feed stock is fed into the spray plume, where the particles are melted and accelerated. HVOF thermal spraydeposited coatings have a lamellar microstructure built up as molten particles deform on impact with the substrate [7]. Porosity caused when splats do not completely match the geometry of the layer below is a problem as it provides a path for corrosion [8]. One of the major advantages of thermal spray processes over other coating techniques is that the particles solidify very rapidly without causing excessive heating to the substrate. The small powder particles are able to very rapidly disperse their heat into the substrate, resulting in rapid solidification rates on the order of $10^{6} \mathrm{~K} \mathrm{~s}^{-1}$ [8]. These rapid solidification rates mean that, when compared to other coating techniques, it is possible to retain a much higher amorphous fraction, something which is suggested to improve corrosion resistance [9]. The rapid solidification rate also acts to limit grain growth, with grain sizes typically not exceeding $5 \mu \mathrm{m}$ [7].

Another alternative coating technique is laser cladding. Laser cladding is a weldtype coating technique which involves using a high powered laser aimed on the surface of the substrate to create a meltpool. The feedstock material is fed, or placed into the laser spot and once in the laser beam, melts and combines with the substrate. On moving out of the laser spot, the newly formed clad bead is allowed to 
cool, solidifying to produce the clad [10]. Laser cladding will typically produce a dense, well-adhered coating with low porosity. The laser-cladding process described above lays down a single track. To create a coating, multiple tracks must be laid side by side to produce a continuous layer. If the track geometry is too circular, or there is not enough overlap, voids can occur at the interpass boundary [11].

Current material choices for heat-exchanger coatings are $\mathrm{Ni}-\mathrm{Cr}$-based alloys, such as Inconel 625. There is obvious economic incentive to using Fe-based alloys as they offer a cheaper alternative to conventionally used Ni-based alloys. In this study, Fe-Cr-B alloy was deposited by both HVOF thermal spray and laser cladding onto a 304 stainless steel substrate. This is a metallic glass forming alloy and by coating with two different methods: thermal spray and laser cladding, known to produce markedly different microstructures, the effects of these microstructures on the high-temperature corrosion were investigated. The novelty of this study lies in the direct comparison of the high-temperature corrosion performance of the two coatings with different amorphous phase fractions.

After deposition, the coatings were then exposed to a high-temperature, controlled environment fireside corrosion test to simulate biomass combustion conditions, in the presence of $\mathrm{KCl}$ deposits for $250 \mathrm{~h}$ at $700{ }^{\circ} \mathrm{C}$. The morphologies and composition of the corroded samples were examined in an SEM with EDX with additional compositional information gained from XRD analysis. Finally, the performance of the coatings was examined on the polished cross section.

\section{Experimental Procedures}

A commercially available feedstock powder Weartech ${ }^{\circledR}$ SHS $^{\mathrm{TM}} 7574$ (The Lincoln Electric Company, $\mathrm{OH})$, with composition $(\mathrm{B}=2.96, \mathrm{Cr}=17.78, \mathrm{Mn}=2.10$, $\mathrm{Mo}=14.24, \mathrm{~W}=5.90, \mathrm{C}=0.88, \mathrm{Al}<0.05, \mathrm{Co}=0.06, \mathrm{Cu}=0.09, \mathrm{Nb}<0.02$, $\mathrm{Ni}=0.13, \mathrm{P}=0.016, \mathrm{Si}=1.36, \mathrm{Sn}<0.02, \mathrm{Ta}<0.02, \mathrm{Ti}<0.02, \mathrm{~V}=0.05$ and Fe balance all in wt\%), measured by AMG Analytical Services, was deposited by HVOF thermal spray and laser cladding onto a 304 stainless steel substrate $(\mathrm{C}<0.08, \mathrm{Cr}<20, \mathrm{Mn}<2, \mathrm{Ni}<12, \mathrm{~N}<0.1, \mathrm{P}<0.045, \mathrm{Si}<0.75, \mathrm{~S}<0.03$ and Fe balance all in wt $\%$ ). The powder had a size fraction of +15 to $53 \mu \mathrm{m}$ with an average particle size of $40.0 \mu \mathrm{m}$, and $10 \%$ of particles were smaller than $23.8 \mu \mathrm{m}$ and $90 \%$ smaller than $66.6 \mu \mathrm{m}$. This was measured using a Mastersizer 3000 (Malvern Instruments, UK). A Met-Jet 4L (Metallisation Ltd, UK) HVOF thermal spray was used to deposit the powder onto $60 \mathrm{~mm} \times 25 \mathrm{~mm} \times 3 \mathrm{~mm}$ coupons of substrate. This is a kerosene-fuelled gun where the powders are injected downstream of the nozzle at a rate of $0.45 \mathrm{~L} \mathrm{~min}^{-1}$, with an $\mathrm{O}_{2}$ flow rate of $862 \mathrm{~L} \mathrm{~min}^{-1}$. Before deposition, the coupons were grit blasted with F100 mesh brown alumina grit and degreased with industrial methylated spirit. The samples were mounted on a rotary carousel with a vertical axis of rotation, and the spray gun traversed the sample surface along the vertical direction at a scan rate of $5 \mathrm{~m} \mathrm{~s}^{-1}$. The speeds were selected as to provide an interpass distance of $4 \mathrm{~mm}$. 
A 2-KW Ytterbium-doped fibre laser (IPG Photonics, Germany) with a $600-\mu \mathrm{m}$ fibre was used to deposit the same feedstock onto a $200 \mathrm{~mm} \times 100 \mathrm{~mm} \times 6 \mathrm{~mm}$ 304 stainless steel plate. This gave a spot size of $4 \mathrm{~mm}$ when used with a $20 \mathrm{~mm}$ defocus. A power of $800 \mathrm{~W}$ and a traverse speed of $300 \mathrm{~mm} \mathrm{~min}^{-1}$ were used to deposit the clad.

A high-temperature, controlled environment corrosion test was performed in a horizontal tube furnace with an internal diameter of $70 \mathrm{~mm}$. The stainless steel reactor used in the furnace was lined with alumina, and the samples were placed in individual alumina crucibles. The dimensions of the samples for the fireside corrosion tests were $10 \mathrm{~mm} \times 10 \mathrm{~mm}$. The test environment contained $500 \mathrm{ppm}$ $\mathrm{HCl}, 5 \% \mathrm{O}_{2}$ and $\mathrm{N}_{2}$ balance at a flow rate at room temperature of $35 \mathrm{~cm}^{3} \mathrm{~min}^{-1}$ for $250 \mathrm{~h}$ at $700{ }^{\circ} \mathrm{C}$. Although this temperature is higher than the conditions that would be experienced in a typical biomass boiler, they were selected so that an appreciable loss could be measured over a short test period.

Before exposure, the samples were degreased and cleaned using ultrasonic agitation in industrial methylated spirit. The samples were split into two groups, each containing a HVOF-sprayed sample and a laser-clad sample. A mixture of $10 \%$ $\mathrm{KCl}$ in industrial methylated spirit slurry was applied on the sample surface with a brush, which after drying deposited an average of $14 \pm 1 \mathrm{mg}$ of $\mathrm{KCl}$ on each sample. The second group of samples was prepared with no deposit. The samples were placed in ceramic crucibles and weighed before exposure. After exposure, the samples were weighed again so the mass gain could be calculated.

$\mathrm{X}$-ray diffraction was used to examine the phases present in the top surface of the samples, both before and after exposure, on a D500 Diffractometer (Siemens AG, Germany) with a diffracted-beam monochromator and scintillation counter detector. The instrument was operated at $40 \mathrm{kV}$ and $20 \mathrm{~mA}$ to generate $\mathrm{Cu} \mathrm{K} \alpha$ radiation at a wavelength of $0.1540 \mathrm{~nm}$. The XRD scans were performed in the range $30^{\circ} \leq 2 \theta \leq 90^{\circ}$ with a step size of $0.08^{\circ}$ and a step dwell time of $8 \mathrm{~s}$. Typical samples for the XRD studies had a surface area of $10 \mathrm{~mm} \times 10 \mathrm{~mm}$.

For the microstructural analysis, the as-sprayed and exposed samples were mounted in cold-mounting resin filled with ballotini for low shrinkage, and the cross-sectional ground and diamond polished to a 1- $\mu \mathrm{m}$ finish. Backscattered Electron images were taken of both the top surface and cross section of each sample on an S-3400N SEM (Hitachi High Technologies, IL) in variable pressure mode with a $20 \mathrm{kV}$ beam voltage. This was accompanied by Energy-Dispersive X-ray Spectrometry on an $\mathrm{x}$-max $80 \mathrm{~mm}^{2}$ spectrometer (Oxford Instruments, UK) to determine the composition of the scales.

\section{Results and Discussion}

\section{As-Deposited Coatings}

Figure 1 shows the phases that were present in the feedstock powder, the assprayed, and the as-clad material. The powder was predominantly amorphous with a broad hump, a typical feature of metallic glasses, seen centred around $44^{\circ}$ [12]. 


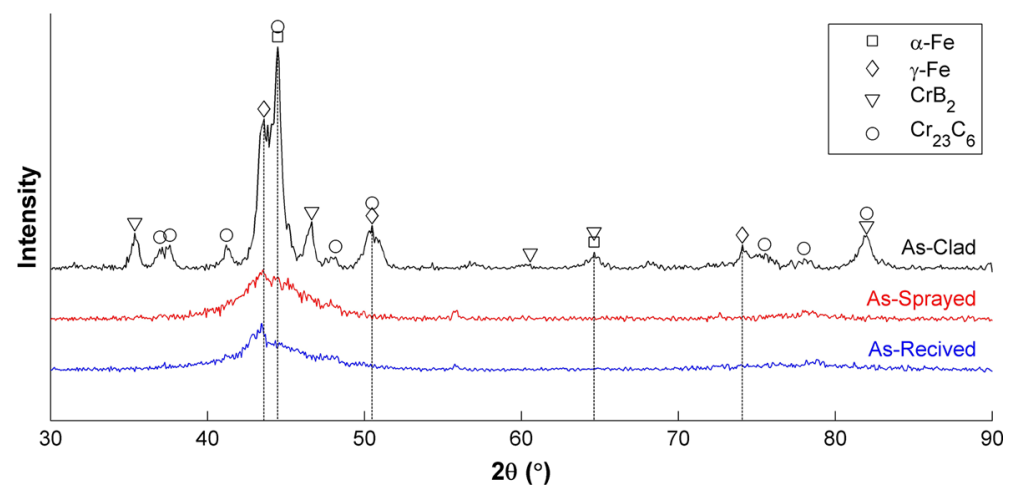

Fig. 1 XRD of Weartech ${ }^{\circledR}$ SHS $^{\text {TM }} 7574$ powder as-received, after coating with HVOF onto a 304 stainless steel substrate and after laser cladding onto a 304 stainless steel substrate

Whilst there were no clearly defined peaks, the broad amorphous hump is centred on a $\gamma$-Fe reflection suggesting that some fraction of the powder had a crystalline structure.

The XRD of the HVOF-sprayed coating showed a slightly broader hump, with a less well-defined peak, corroborating the proposed beneficial effects of HVOF spray in retaining amorphous fraction in metallic glass feedstocks. The literature suggests that thermal spray can retain the amorphous fraction in the feedstock [7, 13-15]. It is suggested that this effect is due to the rapid cooling rates that occur when the molten particles from the spray process are incident on the substrate, on the order of $10^{6} \mathrm{k} \mathrm{s}^{-1}$ [8]. Although after HVOF spray the coating became more amorphous, the characteristic peak of $\alpha$-Fe became visible. This appearance of ferrite is consistent with the process of melting and resolidification of the austenite phase observed in the as-received powder.

The laser-cladding process removed some of the amorphous fraction observed in the as-received powder. The two most prominent peaks in the XRD were still those of the $\gamma$-Fe and $\alpha$-Fe phases. There was also obvious formation of $\mathrm{CrB}_{2}$ and $\mathrm{Cr}_{23} \mathrm{C}_{6}$. Whilst the peaks were more defined, the patterns were much more diffuse than would be expected from a fully crystalline structure, suggesting some amorphous fraction had been retained.

\section{Cross-Sectional Examination and Mass Change}

As-deposited coating cross sections can be seen in Fig. 2. The mean coating thickness before exposure was measured to be $235 \pm 4 \mu \mathrm{m}$ for the HVOF-sprayed coating and $732 \pm 20 \mu \mathrm{m}$ for the laser cladding. The HVOF coating was well bonded to the substrate, and there were no interfacial cracks present at the interface. Occasional porosities were noticed at the splat boundaries as well as within the splat. The laser cladding was metallurgically bonded to the substrate, and there were some gas pores present. Some mixing of the substrate is observed between tracks. Figure 3 shows the cross section of the coatings after exposure both without any 

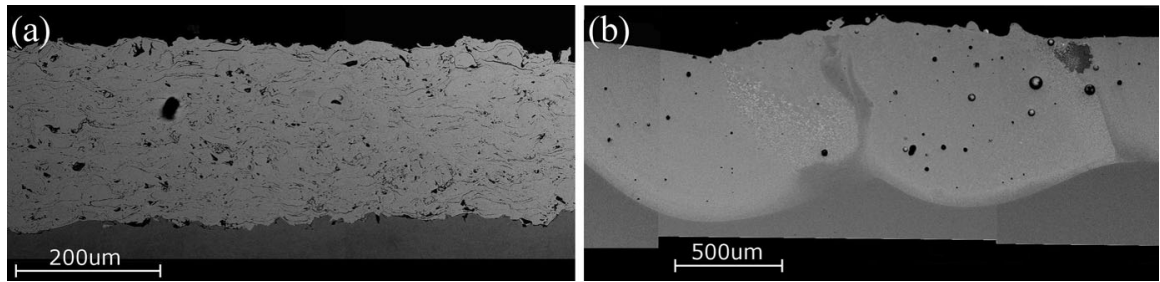

Fig. 2 BSE images showing the cross-sectional microstructure of the a HVOF-sprayed coating and b laser cladding
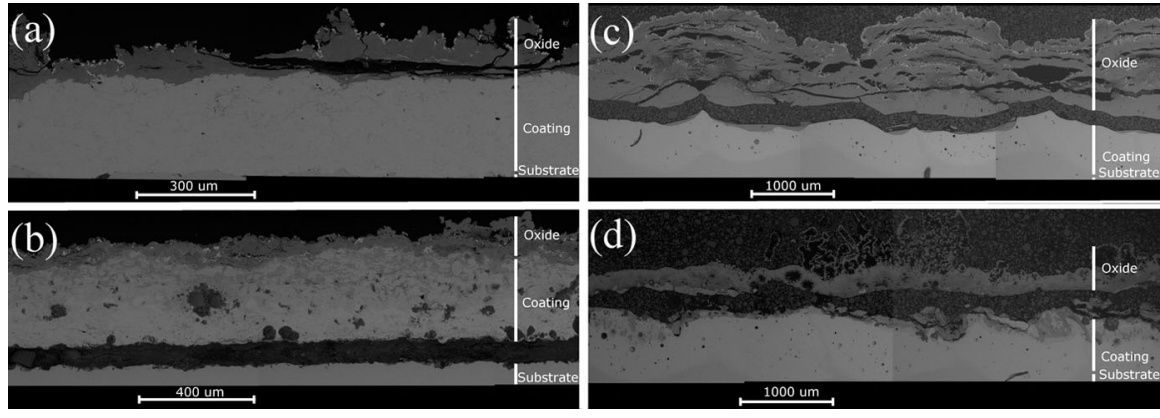

Fig. 3 BSE images showing the cross-sectional microstructure of the a HVOF-sprayed coating with no deposit, b HVOF-sprayed coating with $\mathrm{KCl}$ deposit, $\mathbf{c}$ laser cladding with no deposit and d laser cladding with $\mathrm{KCl}$ deposit

deposit and with the $\mathrm{KCl}$ deposit at $700{ }^{\circ} \mathrm{C}$ for $250 \mathrm{~h}$. The average thickness of the HVOF-sprayed coating without any deposit was $274 \pm 3 \mu \mathrm{m}$, and with $\mathrm{KCl}$ deposit was $276 \pm 7 \mu \mathrm{m}$. This minimal change in thickness has been observed in similar $\mathrm{Fe}-\mathrm{Cr}-\mathrm{B}$ coatings under similar conditions [16]. The laser cladding was strongly affected by the exposure, with an average coating thickness of $381 \pm 24 \mu \mathrm{m}$ for no deposit and $557 \pm 33 \mu \mathrm{m}$ for the $\mathrm{KCl}$ deposit. The HVOF-sprayed coating after exposure with $\mathrm{KCl}$ delaminated from the substrate.

Traditional mass gain data were also recorded for comparison with the literature. The mass gain per unit area of the laser-clad samples was greater than that of the HVOF-sprayed samples both with the $\mathrm{KCl}$ and with no deposit. This shows that HVOF-sprayed samples had a lower oxide formation rate than laser-clad samples in these two environments. The HVOF-sprayed samples showed a mass change per unit area of $43.12 \mathrm{mg} \mathrm{cm}^{-2}$ with no deposit and $130.89 \mathrm{mg} \mathrm{cm}^{-2}$ with the $\mathrm{KCl}$ deposit with an average scale thickness of $80 \pm 17$ and $66 \pm 8 \mu \mathrm{m}$, respectively. These were lower than the observed mass change per unit area of the laser-clad samples which were $153.38 \mathrm{mg} \mathrm{cm}^{-2}$ with no deposit and $166.91 \mathrm{mg} \mathrm{cm}^{-2}$ with the $\mathrm{KCl}$ deposit. The thicknesses of these oxides were $986 \pm 63 \mu \mathrm{m}$ with no deposit and $328 \pm 49 \mu \mathrm{m}$ with a $\mathrm{KCl}$ deposit. This observation was consistent with the proposed benefits of an amorphous microstructure in improving corrosion performance as outlined above. 


\section{Characterization of Corrosion Products}

XRD analysis of the exposed coatings is shown in Fig. 4. The integrity of the HVOF-sprayed coating with $\mathrm{KCl}$ deposit was poor, and it was not possible to use XRD on that sample. Both the HVOF-sprayed and laser-clad samples showed strong reflections from $\mathrm{MnWO}_{4}$, when no deposit was present. This oxide was not detected on the surface of the laser cladding with a $\mathrm{KCl}$ deposit. $\mathrm{MnWO}_{4}$ reacts with gaseous $\mathrm{Cl}_{2}$ to form $\mathrm{MnCl}_{2}$ and $\mathrm{WO}_{2} \mathrm{Cl}_{2}$ [17]. No chlorides were detected on the surface of the samples without any deposit, suggesting that $\mathrm{HCl}$ from the gas did not react to form chlorides, and instead the $\mathrm{KCl}$ deposit was providing the gaseous $\mathrm{Cl}_{2}$ needed for the removal of $\mathrm{MnWO}_{4} \cdot \mathrm{Cr}_{2} \mathrm{O}_{3}$ is another phase that was observed in both the HVOF-sprayed and laser-clad samples without any deposit, but not when $\mathrm{KCl}$ was present. The phase most dominant across all of the samples, however, was $\mathrm{Fe}_{2} \mathrm{O}_{3}$. On the laser-clad sample with the $\mathrm{KCl}$ deposit, the only other major phase identified other than $\mathrm{Fe}_{2} \mathrm{O}_{3}$ was $\mathrm{Fe}_{3} \mathrm{O}_{4}$. It is well established that $\mathrm{Fe}_{2} \mathrm{O}_{3}$ and $\mathrm{Fe}_{3} \mathrm{O}_{4}$ are much less protective than $\mathrm{Cr}_{2} \mathrm{O}_{3}$. This suggests when $\mathrm{KCl}$ was involved the clad material, with $25 \mathrm{wt} \% \mathrm{Cr}$, failed to form a protective chromia layer.

Figure 5 shows the cross-sectional images of both the samples without any deposit and corresponding EDX maps. Figure 5a shows a thick dark contrast oxide layer with a bright oxide phase on top. The external oxide layer was mainly composed of $\mathrm{Fe}$ and $\mathrm{O}$ with a small amount of $\mathrm{Cr}$. This is likely to be a combination of $\mathrm{Fe}_{2} \mathrm{O}_{3}$ and $\mathrm{Fe}_{3} \mathrm{O}_{4}$ as determined by XRD. The $\mathrm{Cr}_{2} \mathrm{O}_{3}$, which was also detected in $\mathrm{XRD}$, is underneath the Fe-rich oxide. $\mathrm{MnWO}_{4}$ was located on the top surface of the Fe-rich oxide. $\mathrm{Cl}$ was not detected in EDX maps in the cross section, suggesting that $\mathrm{HCl}$ did not react with the coating to form any chlorides.

The laser-clad sample is shown in Fig. 5b. The scale thickness was significantly more than that of the HVOF-sprayed sample. It showed many of the same phases as those found in the HVOF-sprayed sample. The oxide layer was mainly composed of $\mathrm{Fe}, \mathrm{Cr}$ and $\mathrm{O}$, with the $\mathrm{Cr}$ present in higher quantities towards the scale-coating

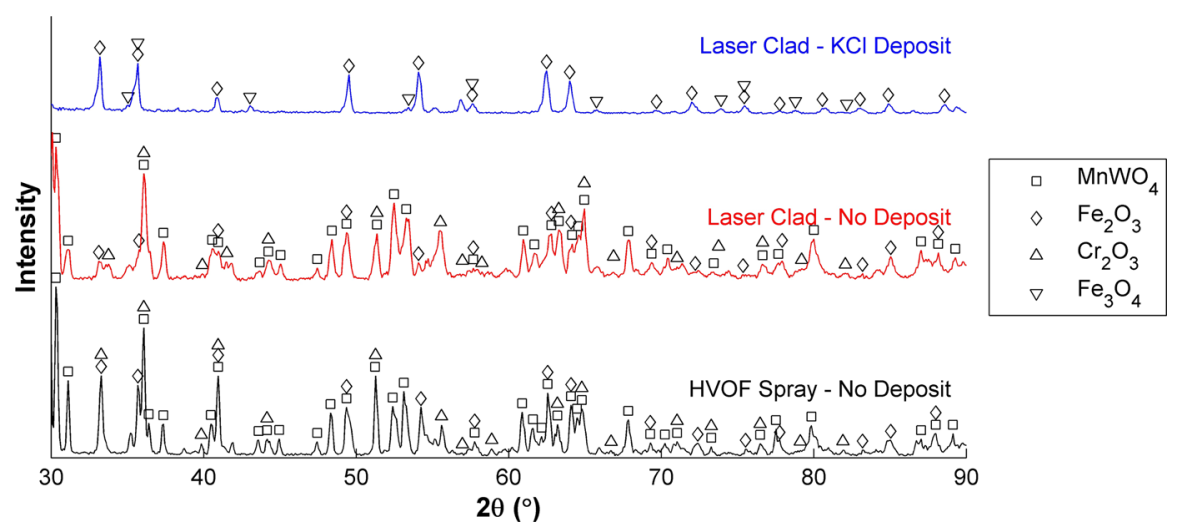

Fig. 4 XRD of HVOF and laser-clad samples after exposure 

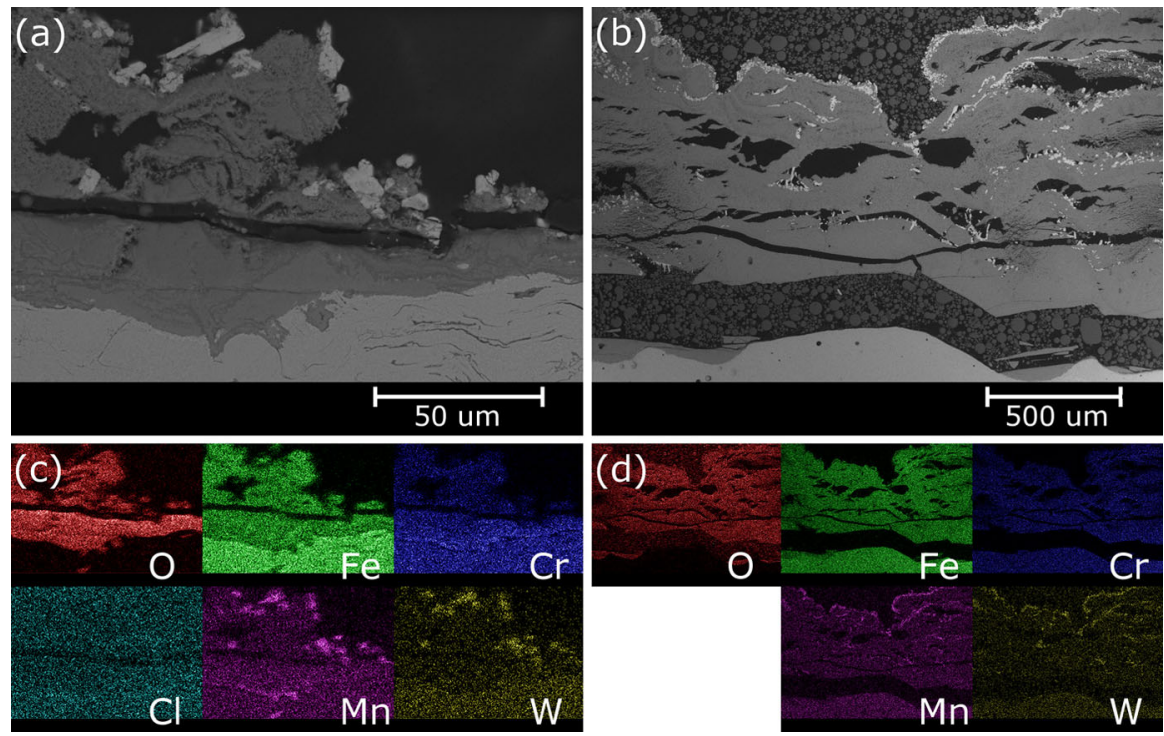

Fig. 5 Cross-sectional BSE images of the HVOF-sprayed (a) and laser-clad (b) samples after $250 \mathrm{~h}$ at $700{ }^{\circ} \mathrm{C}$ with no deposit. The corresponding EDX maps are shown in $\mathbf{c}$ for HVOF coating and $\mathbf{d}$ for laser cladding

interface. EDX analysis of these regions showed the oxides were likely of the same composition as those found in the $\mathrm{HVOF}$-sprayed sample. $\mathrm{MnWO}_{4}$ was also present in the scale of the laser-clad sample, as was confirmed with EDX mapping and XRD.

The cross-sectional images of the samples with deposits are shown in Fig. 6. When comparing these cross sections to those with the $\mathrm{KCl}$ deposit, the most noticeable difference was the presence of $\mathrm{Cl}$ in the scales. $\mathrm{Mn}$ and $\mathrm{O}$ were detected on the outside of the scale with a Fe-rich oxide formed underneath. EDX maps showed another Mn-rich layer contained $\mathrm{Cl}$ embedded within this Fe-rich oxide. EDX spot analysis suggested its composition is close to $\mathrm{MnCl}_{2}$. One mechanism for the formation of $\mathrm{MnCl}_{2}$ is through $\mathrm{MnO}_{2}$ interacting with $\mathrm{HCl}$ via Eq. (1) [18]. This formation process is corroborated by the presence of $\mathrm{Mn}$ and $\mathrm{O}$ which is seen in Fig. 6a as the cubic, fan-like structure at the surface of the sample.

$$
\mathrm{MnO}_{2}+4 \mathrm{HCl} \rightarrow \mathrm{MnCl}_{2}+\mathrm{Cl}_{2}+2 \mathrm{H}_{2} \mathrm{O}
$$

Unlike the samples with no deposits seen in Fig. 5, these $\mathrm{KCl}$-covered samples did not show the $\mathrm{MnWO}_{4}$ phase. A Cr-rich oxide formed underneath the $\mathrm{MnCl}_{2}$. This Cr-rich layer did not contain any $\mathrm{Fe}$, although no $\mathrm{Cr}_{2} \mathrm{O}_{3}$ was detected in the $\mathrm{XRD}$ due to the thickness of the mixed corrosion products. The laser-clad sample after 250-h exposure is shown in Fig. 6b where the mixed corrosion product layer was observed to be over $300 \mu \mathrm{m}$ thick. The outer oxide was a Fe-rich oxide which was porous at the top. The $\mathrm{Cr}$ was only detected below the Fe oxide, an area which 

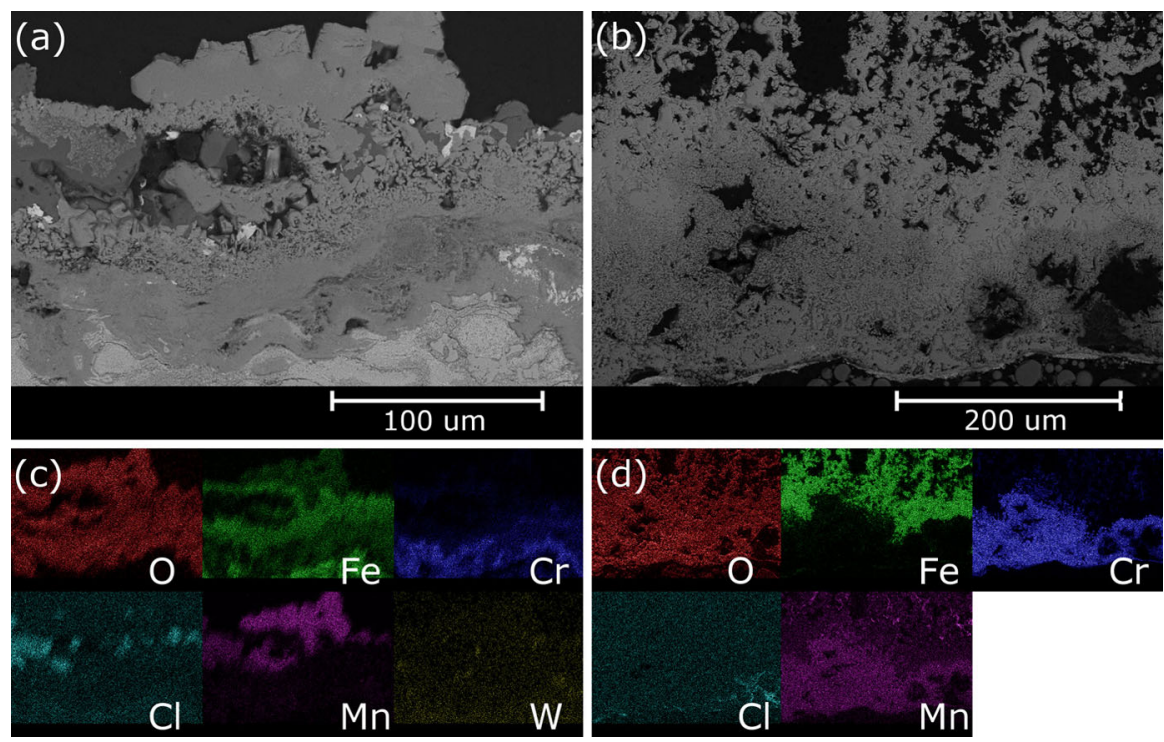

Fig. 6 Cross-sectional BSE images of the HVOF-sprayed (a) and laser-clad (b) samples after $250 \mathrm{~h}$ at $700{ }^{\circ} \mathrm{C}$ with $\mathrm{KCl}$ deposit. The corresponding EDX maps are shown in $\mathbf{c}$ for HVOF coating and $\mathbf{d}$ for laser cladding

also contains $\mathrm{Mn}$. This was a mixture of $\mathrm{Cr}$ and $\mathrm{Mn}$ oxides although there was no $\mathrm{Cr}$ or Mn phase detected in the XRD due to the small penetration depth. $\mathrm{Cl}$ was detected underneath the oxide scales, suggesting that the scales were not protective in nature. $\mathrm{Cl}$ ions can migrate through the non-protective oxide readily.

Figure $7 \mathrm{a}$, c showed the morphology of the oxide scales grown on the HVOFsprayed coating and laser cladding without any deposit. In both cases, the bright phase in the BSE image was detected to be $\mathrm{MnWO}_{4}$. The oxides were rod shaped and grew up to $20 \mu \mathrm{m}$ in length on the HVOF-sprayed coating.

The top surface of the HVOF-sprayed coating with $\mathrm{KCl}$ deposit, Fig. 7b, showed two morphologically different phases. There was an iron oxide phase making up the bulk of the surface similar to all of the other samples; however, this sample was unique in that it had a second, diamond-shaped, iron oxide.

Similarly, there were two distinct textures that could be seen on the surface of the laser-clad sample with a $\mathrm{KCl}$ deposit, Fig. 7d. Small globular-shaped oxides formed the majority of the sample surface, which comprised of Fe and O. EDX and XRD analysis showed it to be $\mathrm{Fe}_{2} \mathrm{O}_{3}$. EDX analysis did not detect any $\mathrm{Cr}$, suggesting this was a very thick region of $\mathrm{Fe}_{2} \mathrm{O}_{3}$. The other region seen on the bottom of Fig. $7 \mathrm{~d}$ showed this is a mix of $\mathrm{Fe}_{2} \mathrm{O}_{3}$ and $\mathrm{Cr}_{2} \mathrm{O}_{3}$. 

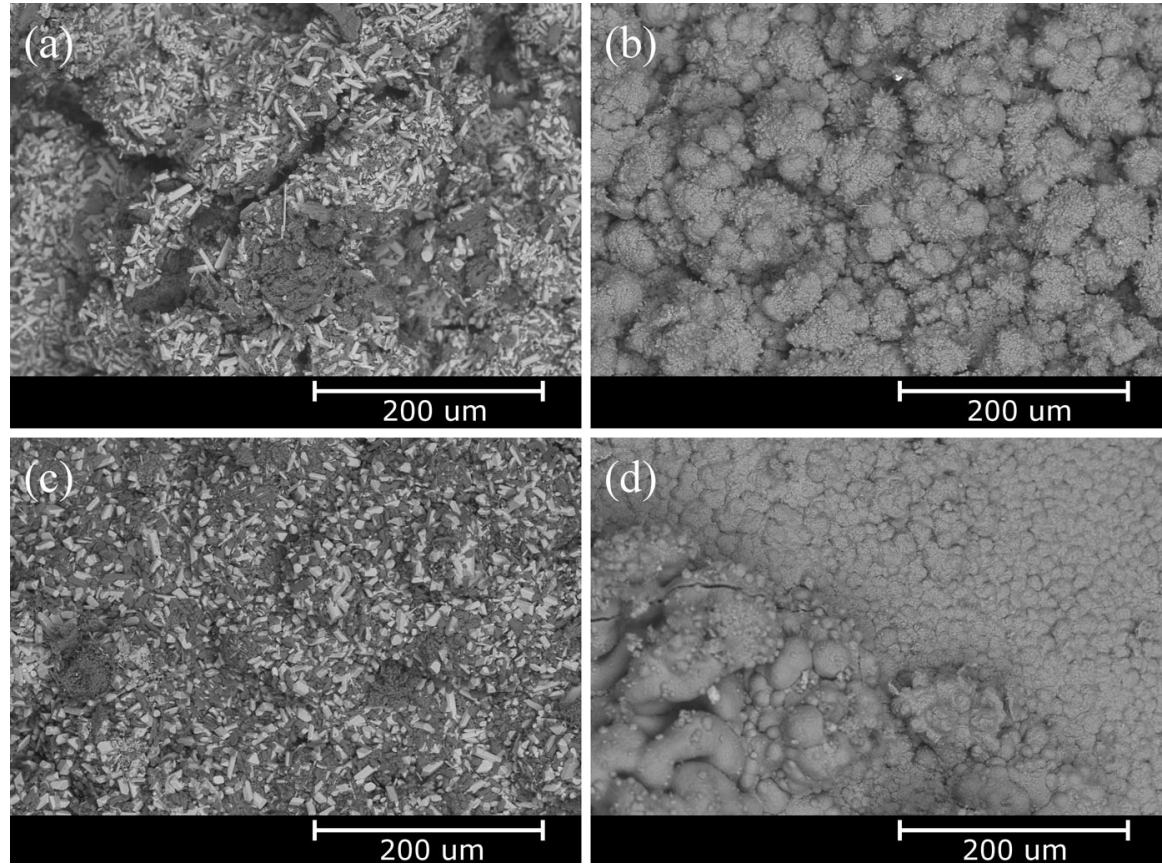

Fig. 7 Top surface after $250 \mathrm{~h}$ in $500 \mathrm{ppm} \mathrm{HCl}, 5 \% \mathrm{O}_{2}, \mathrm{~N}_{2}$ Bal. at $700{ }^{\circ} \mathrm{C}$ a $\mathrm{HVOF}$ spray with no deposit, b $\mathrm{HVOF}$ spray with $\mathrm{KCl}$ deposit, c laser cladding with no deposit, d laser cladding with $\mathrm{HCl}$ deposit

\section{Conclusions}

In this study, an amorphous $\mathrm{Fe}-\mathrm{Cr}-\mathrm{B}$ feedstock was deposited onto a heatexchanger material using HVOF thermal spray and laser cladding. The aim was to understand the corrosion mechanisms of these coatings in a simulated biomass combustion environment. The coated samples were exposed in $500 \mathrm{ppm} \mathrm{HCl}+5 \%$ $\mathrm{O}_{2}$ at $700{ }^{\circ} \mathrm{C}$ for $250 \mathrm{~h}$ without any deposits and with $\mathrm{KCl}$ deposits. The following conclusions can be made:

HVOF thermal spray produced a predominantly amorphous microstructure retaining the phases in the feedstock powder. Laser cladding produced a predominantly crystalline structure with $\alpha-\mathrm{Fe}, \gamma-\mathrm{Fe}, \mathrm{CrB}_{2}$ and $\mathrm{Cr}_{23} \mathrm{C}_{6}$.

Both samples without deposits developed an oxide scale of $\mathrm{MnWO}_{4}, \mathrm{Fe}_{3} \mathrm{O}_{4}$, $\mathrm{Fe}_{2} \mathrm{O}_{3}$ and $\mathrm{Cr}_{2} \mathrm{O}_{3}$. The thickness loss of the HVOF coating was negligible, but the laser-clad sample lost $\sim 350 \mu \mathrm{m}$ in $250 \mathrm{~h}$. The mass gain of the laser-clad sample was three times higher than the HVOF-sprayed coating. The constituent microstructure played a key role in the corrosion behaviour in these environments. It can be concluded that a high amorphous fraction in the material can improve corrosion resistance. 
$\mathrm{MnCl}_{2}$ was detected in both samples when $\mathrm{KCl}$ deposit was used. The scales contained $\mathrm{Fe}_{3} \mathrm{O}_{4}, \mathrm{Fe}_{2} \mathrm{O}_{3}$; however, $\mathrm{MnWO}_{4}$ was not formed. $\mathrm{Cl}$ was detected underneath the oxide scales due to a lack of protective scale formation.

Weartech $^{\circledR}$ SHS $^{\mathrm{TM}} 7574$ coating is a promising candidate coating for heatexchanger components as protective $\mathrm{Cr}_{2} \mathrm{O}_{3}$ was formed under some conditions. Whilst the HVOF-thermal-sprayed coating showed better corrosion performance, the spallation of the coating could be a concern for use in real boiler conditions. Laser-cladded SHS 7574 coating is currently being exposed in a utility-scale biomass-fired power plant in the UK as a part of the field trial.

Acknowledgements Funding was provided by Engineering and Physical Sciences Research Council (Grant No. EP/L016362/1).

Open Access This article is distributed under the terms of the Creative Commons Attribution 4.0 International License (http://creativecommons.org/licenses/by/4.0/), which permits unrestricted use, distribution, and reproduction in any medium, provided you give appropriate credit to the original author(s) and the source, provide a link to the Creative Commons license, and indicate if changes were made.

\section{References}

1. J. Skea and P. Ekins, UKERC Energy 2050 Project: Making the Transition to a Secure and LowCarbon Energy System: Synthesis Report, Report No. S3097 (UKERC, 2009).

2. K. Tokimatsu, R. Yasuoka, and M. Nishio, Applied Energy 185(2), 1899 (2017).

3. N. J. Simms, J. Sumner, T. Hussain and J. E. Oakey, Materials Science and Technology 29(7), 804 (2013).

4. T. Hussain, A. U. Syed and N. J. Simms, Fuel 113, 787 (2013).

5. R. W. Bryers, Progress in Energy and Combustion Science 72, 29 (1995).

6. M. Oksa, S. Tuurna, and T. Varis, Journal of Thermal Spray Technology 22(5), 783 (2013).

7. J. R. Davis, Handbook of Thermal Spray Technology (ASM International, Ohio, 2004).

8. S. J. Bull, J. O. Carlsson, P. R. Charlker, G. Dearnaley, K. S. Fancey, F. C. J. Fellowes, A. S. James, R. Kingswell, A. Leyland, A. Matthews, W. D. Munz, D. S. Rickerby, S. L. Rhode, S. M. Rossnagel, K. T. Scott, and W. M. Steen, Advanced Surface Coatings: A Handbook of Surface Engineering (London, 1991).

9. W. H. Wang, C. Dong and C. H. Shek, Materials Science and Engineering R: Reports 44, 45 (2004).

10. W. M. Steen, Laser Material Processing (Springer, London, 1991).

11. E. Toyserkani, A. Khajepour, and S. Corbin, Laser Cladding (CRC Press, Boca Raton, 2004).

12. R. Babilas, M. Kadziolka-Gawel and A. Burian, Journal of Non-Crystalline Solids 435, 76 (2016).

13. K. Chokethawai, D. G. McCartney, and P. H. Shipway, Journal of Alloys and Compounds 480(2), 351 (2009).

14. M. Oksa and J. Metsäjoki, Journal of Thermal Spray Technology 24(3), 436 (2015).

15. V. K. Balla and A. Bandyopadhyay, Surface and Coatings Technology 205(7), 2661 (2010).

16. S. Tuurna, T. Varis, K. Penttila, S. Holmström, K. Ruusuvuori, S. Holmstro and S. Yli-Olli, Materials and Corrosion 62, (7), 2011 (642).

17. G. C. Fouga, R. M. Taddeo, M. V. Bosco and A. E. Bohe, Thermochimica Acta 536, 30 (2012).

18. V. S. Kolosnitsyn, E. A. Minnikhanova, E. V. Karaseva, Y. K. Dmitriev and M. M. Muratov, Applied Electrochemistry and Corrosion Protection of Metals 76(6), 891 (2005). 